\title{
A Study into Blood Flow, Heart Rate Variability, and Body Surface Temperature While Listening to Music
}

\author{
Kenichi Itao1, Makoto Komazawa1, Hiroyuki Kobayashi ${ }^{2}$ \\ ${ }^{1}$ WINFrontier Laboratory, WINFrontier Co. Ltd., Tokyo, Japan \\ ${ }^{2}$ JUNTENDO University, Tokyo, Japan \\ Email: kenichi.itao@winfrontier.com
}

How to cite this paper: Itao, K., Komazawa, M. and Kobayashi, H. (2018) A Study into Blood Flow, Heart Rate Variability, and Body Surface Temperature While Listening to Music. Health, 10, 181-188. https://doi.org/10.4236/health.2018.102015

Received: January 13, 2018

Accepted: February 8, 2018

Published: February 11, 2018

Copyright ( $) 2018$ by authors and Scientific Research Publishing Inc. This work is licensed under the Creative Commons Attribution International License (CC BY 4.0).

http://creativecommons.org/licenses/by/4.0/

\section{c) (i) Open Access}

\begin{abstract}
In this study we examined the relaxing effects of listening to music on a total of 12 women aged from their 20s to their 40s by measuring their blood flow, heart rate variability, and their body surface temperature. As a result, We found that there was a tendency for the volume of blood flow to the fingertips to significantly increase when listening to classical music, but there was a variety of changes in blood flow between each age group for healing music and J-Pop music. When measuring heart rate it was found that the LF/HF value, which is an index for the autonomic nervous system which shows tension and stress, fell significantly when listening to each type of music. Lastly, there was a trend for body surface temperature to rise when listening to classical or healing music, a rise which was particularly significant when listening to healing music. This study shows that a relaxing effect can be expected for all indices when listening to classical music. However, for healing music and J-Pop, personal musical preferences seemed to have an effect and the results were varied.
\end{abstract}

\section{Keywords}

Music, Blood Flow, Heart Rate Variability, Autonomic Nervous System, Body Surface Temperature

\section{Introduction}

Today's world has long been described as a society of stress, but it is now known that continuous levels of excess stress over long periods of time can induce irregularities in the autonomic nervous system and the secretion of hormones from 
the adrenal cortex, etc. [1]. This can lead to a range of physical and mental disorders, such as high blood pressure, stomach ulcers, and depression [2].

This is why it is so important for individuals to be able to improve their ability to relieve the stress that they experience in their everyday lives.

In recent years, musical therapy has been attracting attention as one way to relieve stress [3], and is often used for purposes other than those in the medical field, such as in the promotion of wellbeing and relaxation.

From a medical standpoint, the effect of using music has been proven to regulate heart rate, blood pressure, and breathing, reduce the level of stress hormones, and improve immunity. It has also been seen to be effective in the reduction of psychological stress [4], [5].

Furthermore, there are previous studies that, after measuring heart rate variability and brain waves, conclude that listening to music has a relaxing effect [6], [7]. However, the number of these studies remains small and there are very few studies that examine multiple indices of the relaxing effect of listening to music.

Therefore this study will use three indices, blood flow, changes in heart rate variability, and body surface temperature to investigate the effect that listening to music has on the mind and body, as well as its comforting effect.

\section{Experiment Description}

\subsection{Subject Selection}

We selected 12 healthy women between their $20 \mathrm{~s}$ and $40 \mathrm{~s}$ (4 women each from the $20 \mathrm{~s}, 30 \mathrm{~s}$, and $40 \mathrm{~s}$ age groups), who had been fully briefed and had agreed to participate in the study. We also acquired informed consent from each subject. In this research, we adopted healthy subjects. (Those who do not have a specific disease).

\subsection{Measurement Indices}

1) Volume of blood flow

We measured the average blood flow flux (PU) on the fingertip of the index finger of each subject using a blood flow sensor [8] (a moorFLPI manufactured by Moor Instruments). This is a piece of blood-flow imaging equipment that measures blood flow through contactless video imaging that uses laser speckling technology. In this study we calculated the average blood flow volume of the middle finger and used it in my analysis.

2) Heart rate variability

Using a heart rate sensor [9] (a WHS-1 manufactured by Union Tool Co.), we fixed this sensor to the chests of our subjects and measured the interval between heartbeats. We then analyzed heart rate variability using specialist software [10] (Advance Viewer Software from WINFrontier Co., Ltd) and calculated the autonomic nervous system. The technique for analyzing the autonomic nervous system conforms with the processes specified in the relevant paper [11] and was calculated using $0.04 \mathrm{~Hz}-0.15 \mathrm{~Hz}$ as a low frequency component (LF) and 0.15 
$\mathrm{Hz}-0.4 \mathrm{~Hz}$ as a high frequency component (HF). The LF/HF values are used as sympathetic autonomic nervous system which represent tension, stimulation, and stress [11]. In this study we will evaluate the degree of stress and relaxation when listening to music using LF/HF.

3) Body surface temperature

We measured body surface temperature using a thermometer (a TIR-308 manufactured by Trusco Nakayama Corporation) and used it in my analysis.

\subsection{Music}

We had our subjects listen to three pieces of music, which were:

1) Classical music ("Pachelbel's Canon" by Orchestre de chambre JeanFrançois Paillard)

2) Healing music ("Harukanaru Kage" by Yumi Nanatsutani ${ }^{\star} A$ cover of "(They Long to Be) Close to You" by The Carpenters)

3) Japanese pop music (J-Pop) ("Exile Pride - Konna Sekai wo Ai suru tame" by Exile)

\subsection{Experiment Protocol}

The flow of each experiment is shown in Figure 1. Once the subjects entered the lab, they were seated in a chair, and after taking a short rest, we began the experiment.

During the experiment, subjects would listen to 5 minutes of silence, followed by 3 minutes of music, followed by 5 more minutes of silence.

The heart rate sensor was attached from the start of the experiment until the end and continuously took heart rate data.

The blood flow sensor measured changes in blood flow volume at the fingertip from just before the music started until the end of the three minutes.

The body surface temperature was measured twice, just before the music started playing and just after. In this study, experiments were conducted three times (once for classical, healing, and J-Pop music) for each of the 12 subjects.

\subsection{Statistical Processing}

We used IBM SPSS Statics Version 22 to process the statistics for the measured data. The significance level of the testing was set at $5 \%$.

\section{Experiment Results}

\subsection{Blood Flow Volume}

Here we compared the blood flow volume as measured by the blood flow sensor at the fingertip before and during the music.

Figure 2 shows the overall average difference in blood flow volume before and while listening to each piece of music. Tables 1-4 show blood flow volume results for each age group and the overall result.

The result showed that as an overall average there was a tendency for blood 


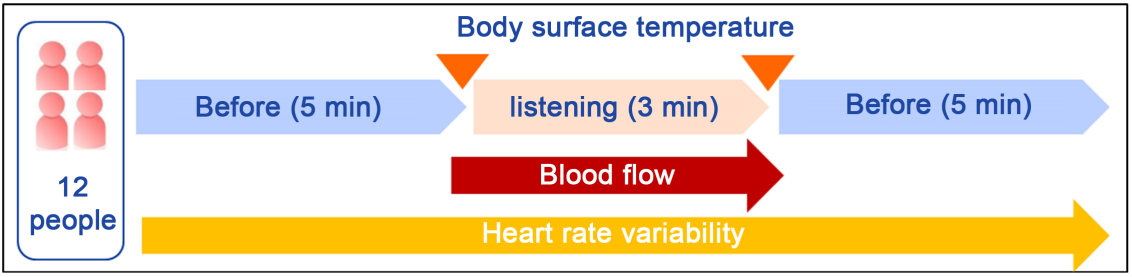

Figure 1. Experiment flow.

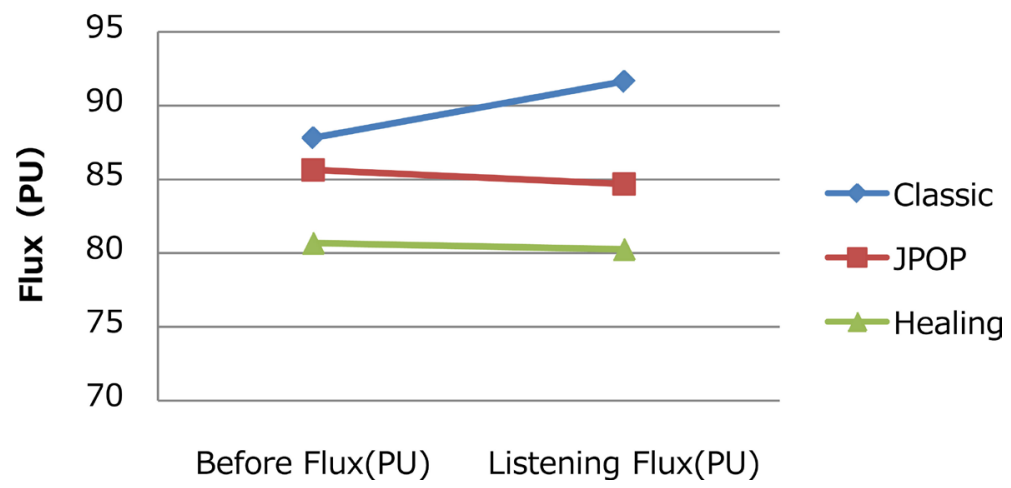

Figure 2. Changes in blood flow before and while listening to music (overall average).

Table 1. Changes in blood flow before and while listening to music (overall average).

\begin{tabular}{ccc}
\hline & Before Flux $(\mathrm{PU})$ & Listening Flux $(\mathrm{PU})$ \\
\hline Classic & $87.8 \pm 21.5$ & $91.6 \pm 22.5$ \\
JPOP & $85.6 \pm 22.4$ & $84.7 \pm 22.2$ \\
Healing & $80.7 \pm 28.1$ & $80.3 \pm 28$ \\
\hline
\end{tabular}

Table 2. Changes in blood flow before and while listening to music (20s group average).

\begin{tabular}{ccc}
\hline & Before Flux $(\mathrm{PU})$ & Listening Flux $(\mathrm{PU})$ \\
\hline Classic & $71.7 \pm 21.6$ & $75.6 \pm 19.3$ \\
JPOP & $68.5 \pm 15.5$ & $68.9 \pm 14.9$ \\
Healing & $54.9 \pm 14.4$ & $55 \pm 17.6$ \\
\hline
\end{tabular}

Table 3. Changes in blood flow before and while listening to music (30s group average).

\begin{tabular}{ccc}
\hline & Before Flux (PU) & Listening Flux (PU) \\
\hline Classic & $86.2 \pm 17.2$ & $86.3 \pm 17.8$ \\
JPOP & $82 \pm 14.7$ & $78.1 \pm 13.6$ \\
Healing & $77.3 \pm 16.3$ & $77.3 \pm 15.5$ \\
\hline
\end{tabular}

Table 4. Changes in blood flow before and while listening to music (40s group average).

\begin{tabular}{ccc}
\hline & Before Flux(PU) & Listening Flux(PU) \\
\hline Classic & $105.6 \pm 12.3$ & $113 \pm 11.3$ \\
JPOP & $106.4 \pm 20.1$ & $107.1 \pm 17.2$ \\
Healing & $109.8 \pm 19.8$ & $108.5 \pm 19.4$ \\
\hline
\end{tabular}


flow volume to rise when listening to classical music compared to the measurement took beforehand. When we carried out a significance test we found a significant difference ( $\mathrm{t}$-test, $\mathrm{p}<0.05)$. However, for J-Pop and healing music, we could not really find a variability in blood flow volume.

Breaking the results down by age group, they show that there was a tendency for blood flow volume to rise when listening to classical music for all age groups, but the results were varied when it came to J-Pop and healing music. These results show that there is a tendency for blood flow to improve when listening to classical music and that it is possible to expect a relaxing effect from it.

\subsection{Heart rate Variability}

Here we compared the measurements taken by the heart rate sensor before, while, and after listening to music. In this study we used the LF/HF value which is used as an index for sympathetic nervous system. The larger the LF/HF value is, the more tension, stimulation, and stress. Figure 3 shows the overall average variability of LF/HF before, during, and after the music. Tables 5-8 show LF/HF results for each age group and overall.

The results show that as an overall average, there was a tendency for LF/HF to fall and for the subjects to relax while listening to the music compared to before

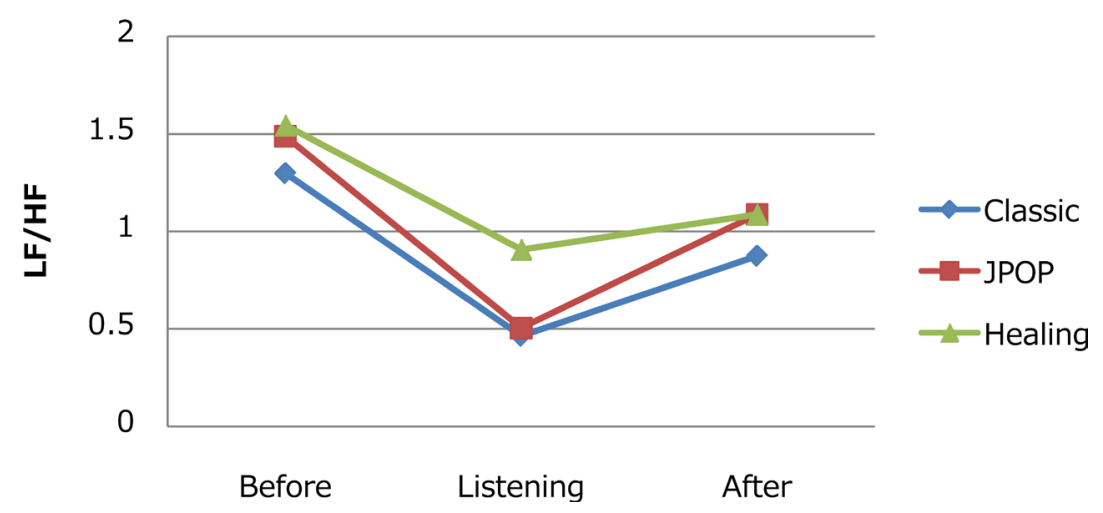

Figure 3. Changes in LF/HF before, while, and after listening to music (overall).

Table 5. Changes in LF/HF before, while, and after listening to music (overall average).

\begin{tabular}{cccc}
\hline & Before & Listening & After \\
\hline Classic & $1.3 \pm 0.66$ & $0.46 \pm 0.46$ & $0.87 \pm 0.82$ \\
JPOP & $1.49 \pm 1.29$ & $0.5 \pm 0.68$ & $1.09 \pm 0.75$ \\
Healing & $1.54 \pm 1.15$ & $0.91 \pm 0.69$ & $1.09 \pm 0.71$ \\
\hline
\end{tabular}

Table 6. Changes in LF/HF before, while, and after listening to music (20s group average).

\begin{tabular}{cccc}
\hline & Before & Listening & After \\
\hline Classic & $1.18 \pm 0.84$ & $0.47 \pm 0.54$ & $0.89 \pm 1.19$ \\
JPOP & $1.44 \pm 0.64$ & $0.54 \pm 0.71$ & $1.1 \pm 0.77$ \\
Healing & $1.63 \pm 1.78$ & $0.56 \pm 0.62$ & $0.96 \pm 0.4$ \\
\hline
\end{tabular}


Table 7. Changes in LF/HF before, while, and after listening to music (30s group average).

\begin{tabular}{cccc}
\hline & Before & Listening & After \\
\hline Classic & $1.41 \pm 0.76$ & $0.27 \pm 0.51$ & $0.71 \pm 0.78$ \\
JPOP & $1.53 \pm 2.02$ & $0.42 \pm 0.91$ & $0.99 \pm 0.48$ \\
Healing & $1.29 \pm 0.84$ & $1.52 \pm 0.93$ & $1.24 \pm 1.18$ \\
\hline
\end{tabular}

Table 8. Changes in LF/HF before, while, and after listening to music (40s group average).

\begin{tabular}{cccc}
\hline & Before & Listening & After \\
\hline Classic & $1.59 \pm 0.58$ & $0.69 \pm 0.44$ & $1.06 \pm 0.65$ \\
JPOP & $1.6 \pm 0.85$ & $0.56 \pm 0.3$ & $1.2 \pm 1.08$ \\
Healing & $1.56 \pm 0.69$ & $0.36 \pm 0.06$ & $1.29 \pm 0.55$ \\
\hline
\end{tabular}

and afterwards. When we carried out a significance test we found a tendency for a significant reduction in LF/HF for each piece of music when comparing measurements before the music and while listening ( $t$-test, $\mathrm{p}<0.05)$. When comparing the measurements taken while listening to the music and after it finished, we found a tendency for a significant fall in LF/HF for classical and healing music while the subject was listening ( $t$-test, $\mathrm{p}<0.05)$. Even when the results are broken down by age group, despite the fact that they show a rise in LF/HF for women in their 30's while listening to healing music, all of the other results tended to conform to the overall average.

These results show that while listening to music sympathetic nervous system is suppressed and parasympathetic nervous system is heightened, meaning a relaxing effect can be expected.

\subsection{Body Surface Temperature}

Here we compared the difference in body surface temperature taken before the music began and while listening to the music.

Figure 4 shows the overall average difference in body surface temperature from before listening to the music and while listening to the music for each piece of music. Tables 9-12 show temperature results for each age group and the overall result.

The result of these experiments show that, as an overall average, body surface temperature did rise after listening to both classical and healing music. Each age group generally conforms with the overall tendency. A tendency can be seen for a particularly significant rise in body surface temperature while listening to healing music (t-test, $\mathrm{p}<0.05)$.

\section{Conclusions}

In this study we examined the relaxing effect of listening to music on 12 women who are in their 20s, 30s and 40s by measuring blood flow, heart rate variation, and body surface temperature. 


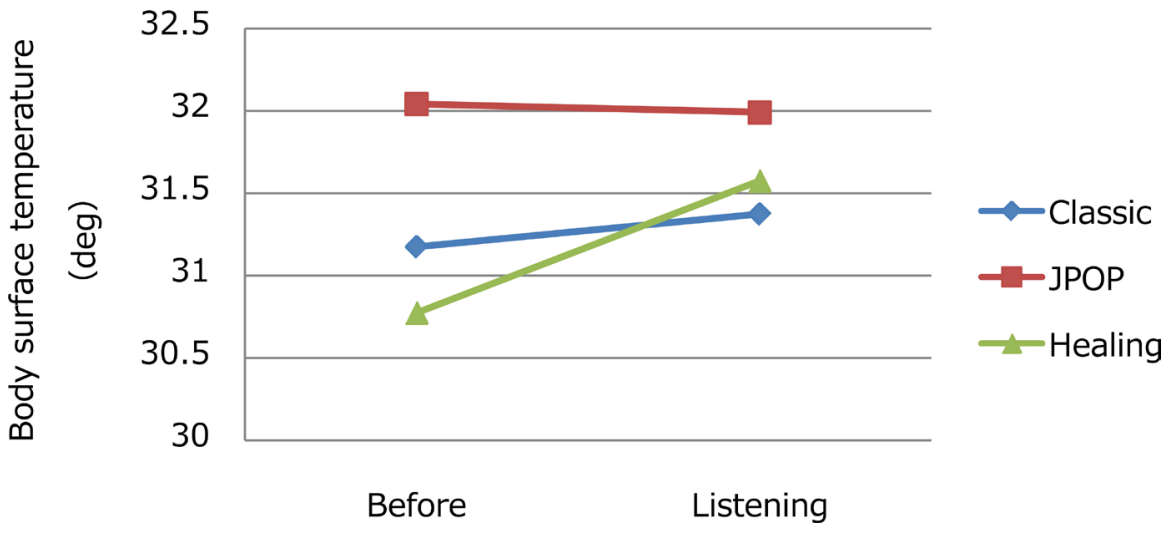

Figure 4. Change in body temperature before and while listening to music (overall average).

Table 9. Change in body temperature before and while listening to music (overall average).

\begin{tabular}{ccc}
\hline & Before & Listening \\
\hline Classic & $31.2 \pm 1.3$ & $31.4 \pm 1.1$ \\
JPOP & $32 \pm 1.3$ & $32 \pm 1.4$ \\
Healing & $30.8 \pm 1.6$ & $31.6 \pm 1.7$ \\
\hline
\end{tabular}

Table 10. Change in body temperature before and while listening to music (20's group average).

\begin{tabular}{ccc}
\hline & Before & Listening \\
\hline Classic & $31.1 \pm 1.6$ & $31.4 \pm 1.2$ \\
JPOP & $31.4 \pm 1.7$ & $31.2 \pm 1.5$ \\
Healing & $30.1 \pm 1.5$ & $30.5 \pm 1.5$ \\
\hline
\end{tabular}

Table 11. Change in body temperature before and while listening to music (30's group average).

\begin{tabular}{ccc}
\hline & Before & Listening \\
\hline Classic & $31.2 \pm 1.6$ & $31 \pm 1.1$ \\
JPOP & $31.6 \pm 0.6$ & $31.5 \pm 0.5$ \\
Healing & $30.1 \pm 1.7$ & $30.8 \pm 0.4$ \\
\hline
\end{tabular}

Table 12. Change in body temperature before and while listening to music (40's group average).

\begin{tabular}{ccc}
\hline & Before & Listening \\
\hline Classic & $31.2 \pm 0.8$ & $31.8 \pm 1.2$ \\
JPOP & $33.2 \pm 0.9$ & $33.3 \pm 1.3$ \\
Healing & $32.1 \pm 1.1$ & $33.5 \pm 0.9$ \\
\hline
\end{tabular}

The results show that there is a tendency for a significant rise in blood flow volume at the fingertips when listening to classical music, and that this result 
was more varied by age group for J-Pop and healing music. We think that this may be due to differences in musical preferences, etc., between the generations.

For heart rate variability, there was a tendency for the LF/HF values, which represent the index for the autonomic nervous system, which in turn indicates the degree of tension or stress a person is experiencing, to significantly fall while listening to each piece of music.

Lastly, there was a tendency for body surface temperature to significantly rise while listening to classical or healing music, and this rise was particularly pronounced when listening to healing music.

As a result of this study, there is a tendency to be able to expect a relaxing effect when listening to classical music using each index. On the other hand, personal musical preferences can be thought to have had an effect on the results for healing and J-Pop music and these results were more varied.

In the future we would like to continue my research into the relaxing effect of listening to music while taking personal musical preferences into account and using multiple indices

\section{References}

[1] Onaka, T. (2005) Stress and Its Neural Mechanisms. Journal of Pharmacological Sciences, 126, 170-173.

[2] Agari, I. and Takenaka, K. (2005) Sutoresu Manejimeno- "Kore Made" to "Kore Kara” [Stress Management- "Until Now" and "From Now”]. Yumani Shobo, 9, 4-6.

[3] Urakawa, K. (2003) Rirakuseshon Puroguramu ni Okeru Ongaku ni Okeru Shinriteki Kouka [The Psychological Effects of Music in Relaxation Programs]. Nihon Ongaku Ryoho Gakkaishi, 3, 71-78.

[4] Kotake, N., Nakamura, K. and Takahashi, Y. (2004). Ongaku Ryoho no Rirakuseshon Kouka ni Kan suru Kenkyu [Research into the Relaxing effect of Musical Therapy]. Kenritsu Nagasaki Shiboruto Daigaku Kango Eiyogakubu Kiyo, 5, 1-10.

[5] Hinohara, S. (2002) Ongaku Ryoho no Maukaubeki Michi [Where We Should Turn in Musical Therapy]. Nihon Ongaku Ryoho Gakkaishi, 2, 1-10.

[6] Hori, K., Senga, Y., Minami, S. and Hori, S. (2004) Ongaku Choshu ga Shinpaku Hendo ni Oyobosu Eikyo [The Effect of Listening to Music on Heart Rate Variance]. Nihon Seikisho Gakkaishi, 41, 131-140.

[7] Fujimoto, C., et al. (2002) Ongaku Kanshochu ni Okeru Arufa Taiiki Seibun to Shinpaku Hendo no Kankei [Alpha Band Components in Music Appreciation and their Relationship to Heart Rate Variance]. Kagawa Kenritsu Iryo Tanki Daigaku Kiyo, 4, 129-131.

[8] Moor Instruments, moorFLPI. http://gb.moor.co.uk/product/moorflpi-moorflpi/4

[9] WHS-1 from Union Tool Co. http://uniontool.co.jp/product/sensor/index_02.html

[10] Advance Viewer Software from WINFrontier Co., Ltd. http://www.winfrontier.com/sensor.html

[11] Task Force of the European Society of Cardiology and the North American Society of Pacing and Electrophysiology (1996) Heart Rate Variability: Standards of Measurement, Physiological Interpretation, and Clinical Use. Circulation, 93, $1043-$ 1065. https://doi.org/10.1161/01.CIR.93.5.1043 